\title{
VMAT2 Gene Molecular study of 2,000 peoples in the Religious Behavior and Belief in God of the citizens of the city of Tabriz in IRAN
}

\author{
Shahin Asadi ${ }^{*}$, Zahra Gholizadeh ${ }^{1}$, Mahsa Jamali², Ali Nazirzadeh ${ }^{3}$, Saeedeh Habibi ${ }^{3}$ \\ ${ }^{1,2}$ Stem Cells Research Center of Oncology and Hematology and Research Center of Human Genetics Tabriz University of Medical Sciences in Iran \\ 1,2Young Researchers Club and the elite Islamic Azad University of Tabriz, Iran \\ ${ }^{3}$ Young Researchers Club and the elite Islamic Azad University of Ahar, Iran
}

Received: September 30, 2016; Accepted: October 19, 2016; Published: October 29, 2016

*Corresponding author: Shahin Asadi, Stem Cells Research Center of Oncology and Hematology Tabriz University of Medical Sciences in Iran, Young Researchers Club and the elite Islamic Azad University of Tabriz, Iran, Tel: +989379923364; E-mail: Shahin.asadi1985@gmail.com

\begin{abstract}
Belief in God and worship him, a natural need and man's inner state that Adam and Eve Angel, has been retained to this day. Decades of communism in the world of religious authority, could this natural need of the human and spiritual surrender. Man is always in crisis situations where social or environmental damage, learning is more evident upon him. And in such situations the natural need of the human and esoteric activity of several genes, is written. But a gene crucial role to play in this need of God and the name of the gene VMAT2 is. And the role of this gene in the human being religious, we have evaluated. In this study of 2,000 people of whom 1,000 religious and 1,000 others were less religious were analyzed.
\end{abstract}

Keywords: Believe in God, VMAT2 Gene, Adam \& Eva, Pray God, PCR, 2000 people of Tabriz city, IRAN

\section{Introduction}

The God gene hypothesis proposes that a specific gene, called vesicular monoamine transporter 2 (VMAT2), predisposes humans towards spiritual or mystic experiences. The idea has been postulated by geneticist Dean Hamer, the director of the Gene Structure and Regulation Unit at the U.S. National Cancer Institute, and author of the 2005 book The God Gene: How Faith is Hard wired into our Genes.

The God gene hypothesis is based on a combination of behavioral genetic, neurobiological and psychological studies. The major arguments of the hypothesis are: (1) spirituality can be quantified by psychometric measurements; (2) the underlying tendency to spirituality is partially heritable; (3) part of this heritability can be attributed to the gene VMAT2; [1] (4) this gene acts by altering monoamine levels; and (5) spiritual individuals are favored by natural selection because they are provided with an innate sense of optimism, the latter producing positive effects at either a physical or psychological level. According to this hypothesis, the God gene (VMAT2) is a physiological arrangement that produces the sensations associated, by some,

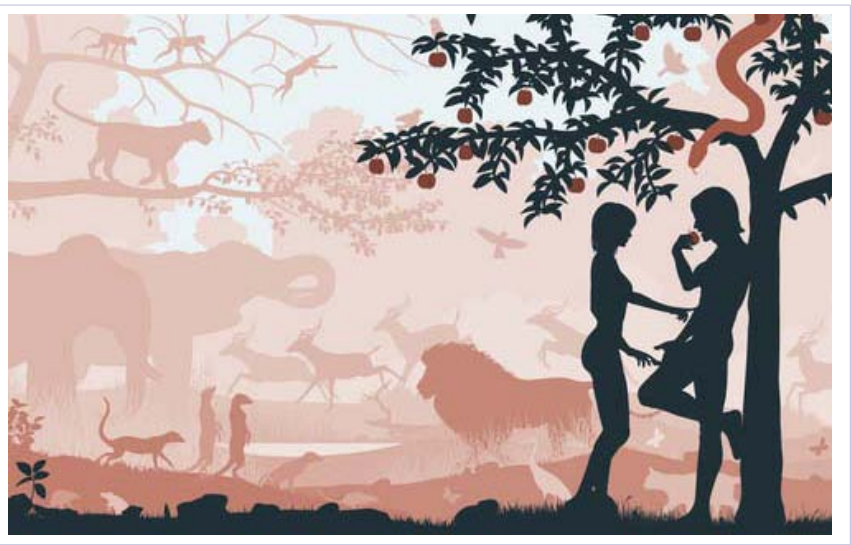

Figure 1: Schematic view of Adam and Eve in the ground.

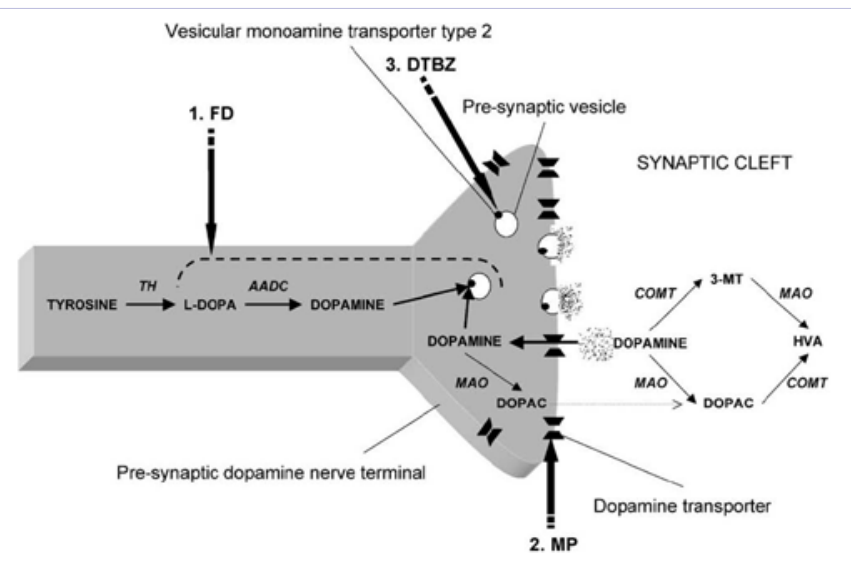

Figure 2: Schematic view of how the VMAT2 gene in human cells.

with mystic experiences, including the presence of God or others, or more specifically spirituality as a state of mind.

Based on research by psychologist Robert Cloninger, 
this tendency toward spirituality is quantified by the selftranscendence scale, which is composed of three sub-sets: "selfforgetfulness" (as in the tendency to become totally absorbed in some activity, such as reading); "transpersonal identification" (a feeling of connectedness to a larger universe); and "mysticism" (an openness to believe things that remain unproven, such as ESP) (This is an incorrect definition of mysticism). Cloninger suggests that taken together, these measurements are a reasonable way to quantify (make measurable) how spiritual someone is feeling.

The self-transcendence measure was shown to be heritable by classical twin studies conducted by Lindon Eaves and Nicholas Martin. Interpreters of these studies argue that specific religious beliefs (such as belief in Jesus) have no genetic basis and are instead memes,[citation needed] cultural units transmitted by imitation (non genetic means).

In order to identify some of the specific genes involved in self-transcendence, Hamer analyzed DNA and personality score data from over 1000 individuals and identified one particular locus, VMAT2, with a significant correlation. VMAT2 codes for a vesicular monoamine transporter that plays a key role in regulating the levels of the brain chemicals serotonin, dopamine and norepinephrine. These monoamine transmitters are in turn postulated to play an important role in regulating the brain

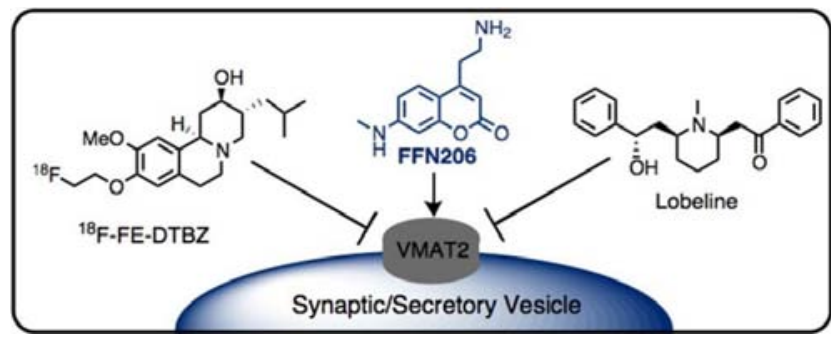

Figure 3: Schematic view of chemical structure VMAT2 gene in human cells.
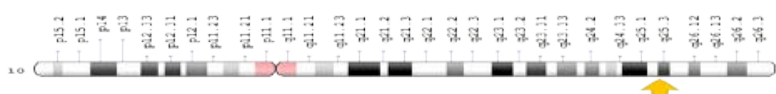

Figure 4: Schematic view of the VMAT2 gene on the long arm of chromosome 10 in human cells.
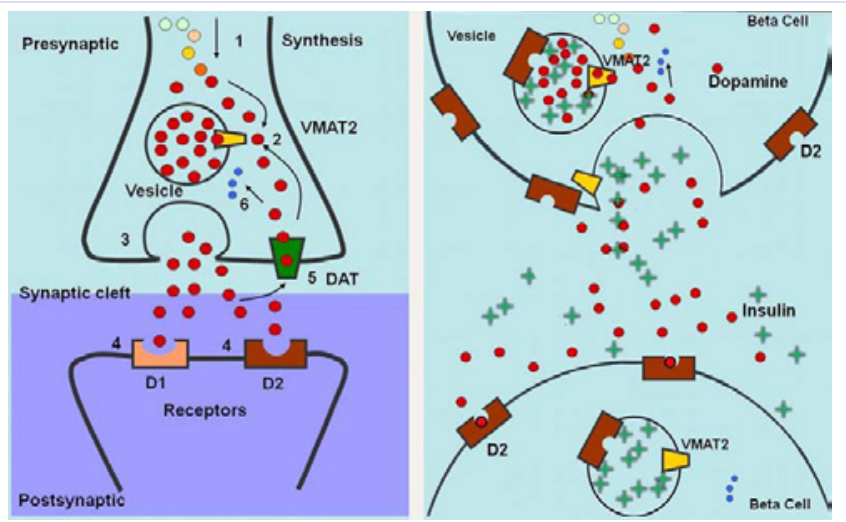

Figure 5: Schematic view of the VMAT2 gene in neural interactions with receptors on human cells.

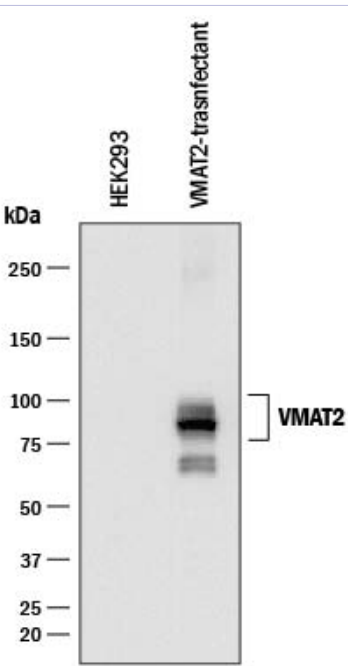

Figure 6: Schematic view of the banding pattern and formed a band in the gene VMAT2.
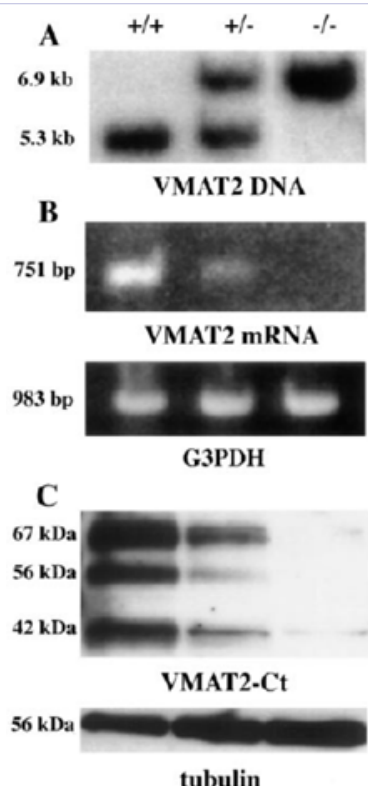

Figure 7: Schematic view of the band pattern on agarose gels for VMAT2 gene in DNA and mRNA molecules and tubulin.

activities associated with mystic beliefs.

The evolutionary advantage this might convey, or whether it could be a side effect of a separate adaptation, have yet to be fully explored. However, Dr. Hamer has hypothesized that selftranscendence makes people more optimistic, which makes them healthier and likely to have more children.

Although it is always difficult to determine the many interacting functions of a gene, VMAT2 appears to be involved in the transport of monoamine neurotransmitters across the synapses of the brain. PZ Myers argues: "It's a pump. A teenytiny pump responsible for packaging a neurotransmitter for export during brain activity. Yes, it's important, and it may even be active and necessary during higher order processing, like religious thought. But one thing it isn't is a 'god gene?' [2]. 
Carl Zimmer claimed that VMAT2 can be characterized as a gene that accounts for less than one percent of the variance of self-transcendence scores. These, Zimmer says, can signify anything from belonging to the Green Party to believing in ESP. Zimmer also points out that the God Gene theory is based on only one unpublished, unreplicated study [3]. However Hamer notes that the importance of the VMAT2 finding is not that it explains all spiritual or religious feelings, but rather that it points the way toward one neurobiological pathway that may be important.

The vesicular monoamine transporter 2 (VMAT2) also known as solute carrier family 18 member 2 (SLC18A2) is a protein that in humans is encoded by the SLC18A2 gene [4]. VMAT2 is an integral membrane protein that transports monoamines-particularly neurotransmitters such as dopamine, norepinephrine, serotonin and histamine from cellular cytosol into synaptic vesicles [5] In nigrostriatal pathway and mesolimbic pathway dopaminereleasing neurons, VMAT2 function is also necessary for the vesicular release of the neurotransmitter GABA [6]

One binding site is that of dihydrotetrabenazine (DTBZ) and reserpine. Lobeline binds at this site. Amphetamine (TBZ site) and methamphetamine (reserpine site) bind at distinct sites to on VMAT2 to inhibit its function [7]. Although the amphetamines inhibit VMAT2 presynaptically leading to diminished neurotransmitter, the primary mechanism for the enhancement of extracellular monoamines, like dopamine, is reversal of the dopamine transporter (DAT) [8]. Other VMAT2 inhibitors such as GZ-793A inhibit the reinforcing effects of methamphetamine, but without producing stimulant or reinforcing effects themselves [9].

VMAT2 is essential in the presynaptic neuron's ability to facilitate the release of neurotransmitters into the synaptic cleft. If VMAT2 function is inhibited or compromised neurotransmitters, such as dopamine, cannot be released via normal transport (exocytosis, action potential) into the synapse.
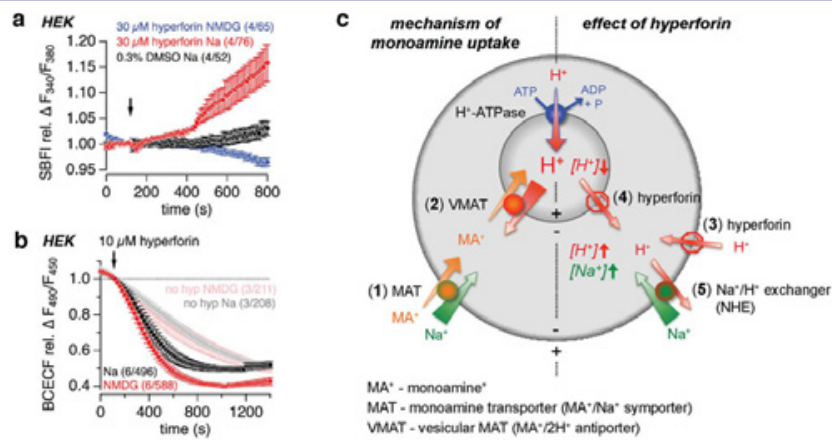

Figure 8: Schematic view of the mechanism of action of VMAT2 gene along with its variance in DMSO.
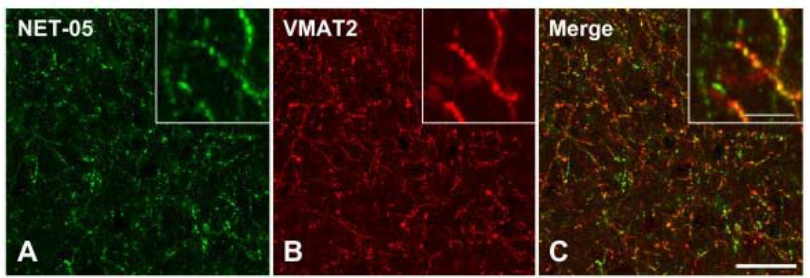

Figure 9: Microscopic view of his genes VMAT2 men participating in the study of the nervous tissue.
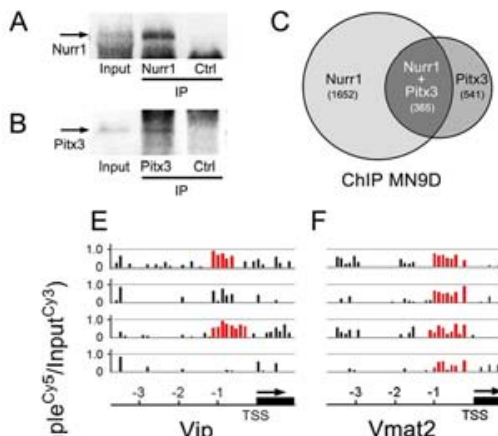

$\mathrm{F}$

Holl the Illunls at

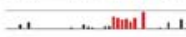

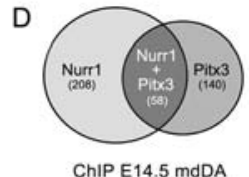

G

hat .al ullatil.

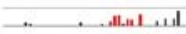

$\stackrel{-3}{2} \stackrel{2}{2}: \frac{1}{2} \underset{T S S}{\longrightarrow}$

Vmat2

I

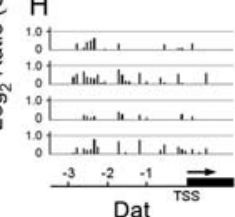

K

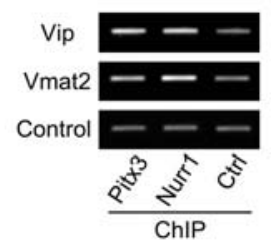

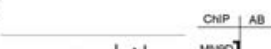

(1)
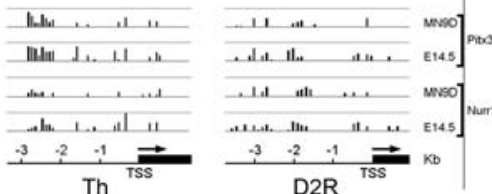

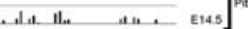

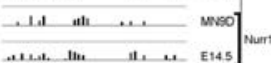

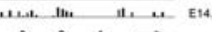

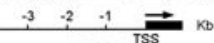

$\mathrm{D} 2 \mathrm{R}$

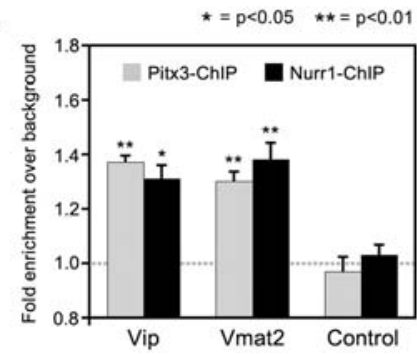

Figure 10: Schematic view of gene expression and activity diagrams frequency VMAT2 religious and nonreligious people.

VMAT2 function inhibition can have many various effects on neurotransmitter function. Specifically of importance is its effect on the neurotransmitter dopamine.

Cocaine users display a marked reduction in VMAT2 immunoreactivity. Sufferers of cocaine-induced mood disorders displayed a significant loss of VMAT2 immunoreactivity; this might reflect damage to dopamine axon terminals in the striatum. These neuronal changes could play a role in causing disordered mood and motivational processes in more severely addicted users [10].

\section{Materials and Methods}

The study of 2,000 people of whom 1,000 and 1,000 others were pious religious people and religious people in low grade was used. We chose the 1000 religious man from among those who have always participated in the prayers of God and always friendly and good things God had done. And 1,000 others among those who never attend religious services once during their life and God were not friendly company, chose As well as the people never done good work and God were friendly.

After obtaining written consent from all individuals participating in the study, blood samples were taken to 10 ml. Peripheral blood samples and the samples are mixed and combined with EDTA were frozen at a temperature of $-70 c^{\circ}$. Then the people from peripheral blood samples, DNA was extracted by PCR. DNA extracted from whole blood using standard methods carried out and the quality of DNA were analyzed by OD 260/280 absorption rate and in all cases the ratio is between $1 / 7-1$ 
/ 9, respectively. DNA kits Hilden Germany QiaGene product according to the manufacturer's protocol contained in brochures product was extracted. The extracted DNA was washed in $20 \mathrm{ml}$ Tris-EDTA solution containing (20 $\mathrm{mm}$ Tris and $2 \mathrm{~mm}$ EDTA) and were kept at a temperature of $-20 c^{\circ}$. This study was used for polymerase chain reaction PCR and primers used were designed using information from NCBI genomic database.

Gene, VMAT2, which in the long arm of chromosome 10 is located on 10q26.1 form. In exon 1 gene VMAT2 by Master Cycler, micro initially for 120 seconds at $95^{\circ} \mathrm{C}$ were heated and then 20 seconds at $95^{\circ} \mathrm{C}$ and 60 seconds at $72^{\circ} \mathrm{C}$ for 5 times, and next, the sequence 25 times in 20 seconds at $95^{\circ} \mathrm{C}, 20$ seconds temperature of $67^{\circ} \mathrm{C}$ and 40 seconds at a temperature of 72 degrees was heated. PCR product using $2 \%$ agarose gel containing ethidium bromide was evaluated by trans RPL. Analyze data using SPSS software version of bioinformatics and population genetics to study the $\chi 2$ test was performed with $95 \%$ confidence.

The mean age of 39.3 years and the average age of the secular religious people were 41.1 years. Fearing religious people uprooted in this study, 500 male and 500 were female and 500 male and 500 non-religious were female.

VMAT2 gene nucleotide sequence was obtained as follows:

>gi|349711|gb|L23205.1|HUMVMAT2 Human vesicle monoamine transporter (VMAT2) mRNA, complete cds
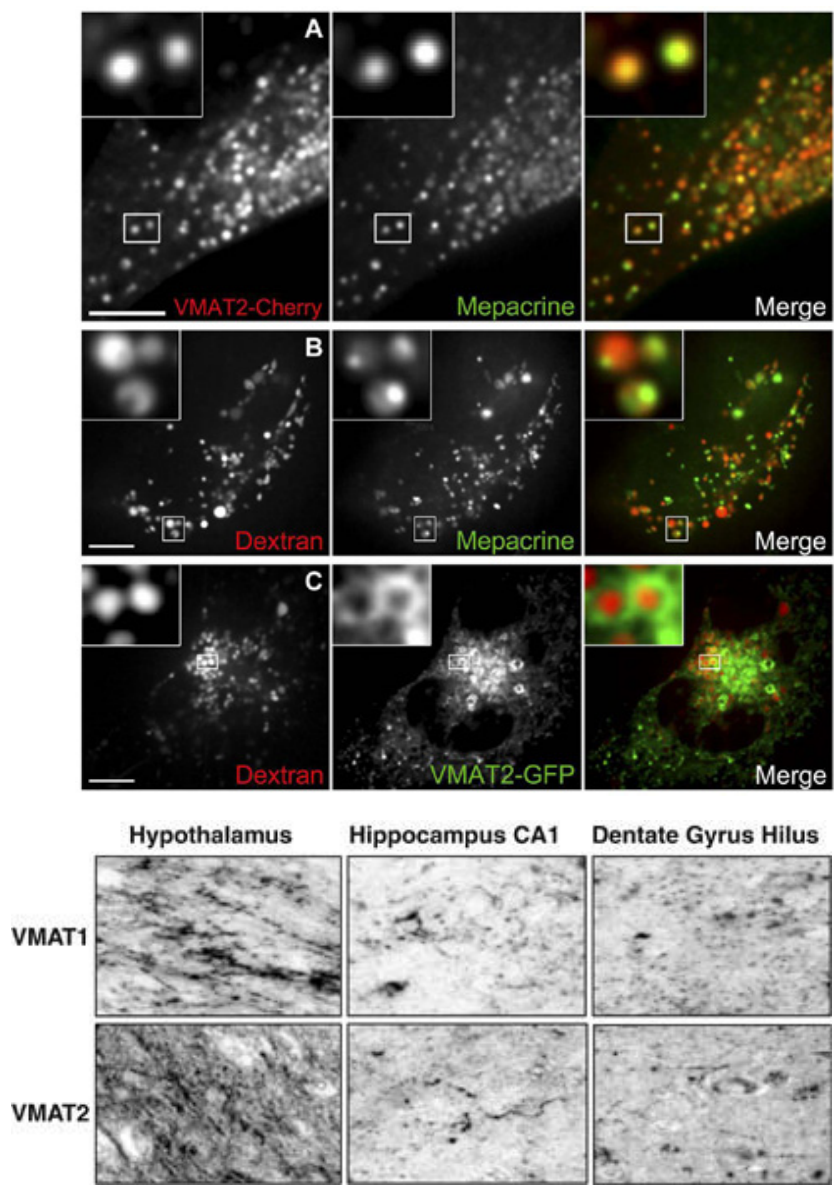

Figure 11: Overview of the field phase contrast microscopy VMAT2 gene.
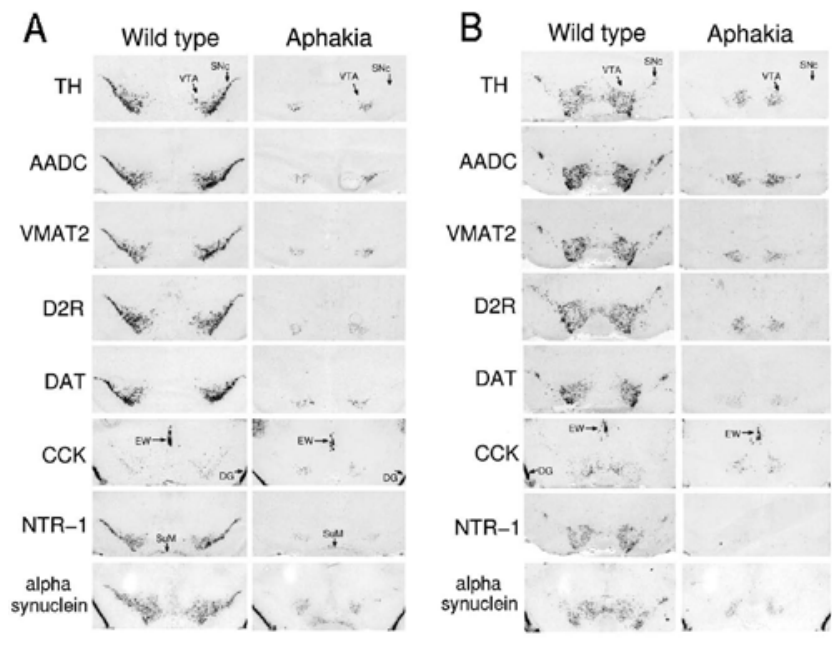

Figure 12: Microscopic view of genes TH, AADC, VMAT2, 2R, DAT, CCK, NTR-1, Alpha Synuclein.

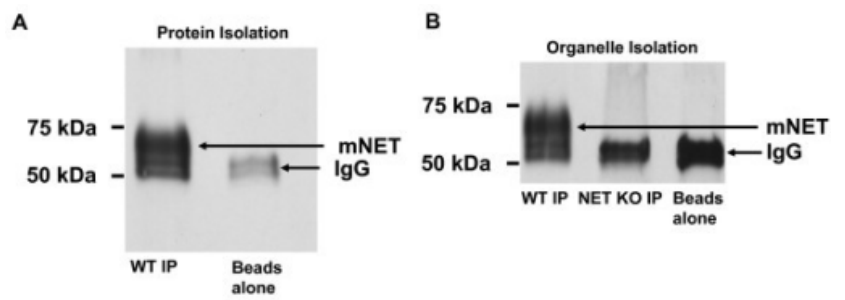

C

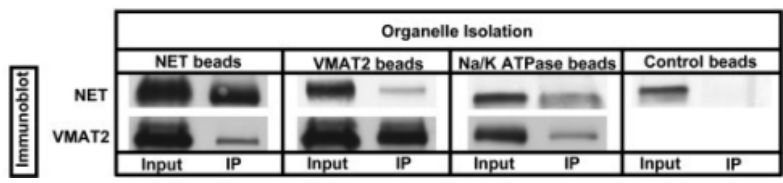

Figure 13: Schematic view of the banding patterns and single-band Genes VMAT2 and NET.

ACTGCGACCCGGAGCCGCCCGGACTGACGGAGCCCACTGCGGTGCGGGCGTTGGCGCGGGCACGGAGGAC

CCGGGCAGGCATCGCAAGCGACCCCGAGCGGAGCCCCGGAGCCATGGCCCTGAGCGAGCTGGCGCTGGTC

CGCTGGCTGCAGGAGAGCCGCCGCTCGCGGAAGCTCATCCTGTTCATCGTGTTCCTGGCGCTGCTGCTGG

ACAACATGCTGCTCACTGTCGTGGTCCCCATCATCCCAAGTTATCTGTACAGCATTAAGCATGAGAAGAA

TGCTACAGAAATCCAGACGGCCAGGCCAGTGCACACTGCCTCCATCTCAGACAGCTTCCAGAGCATCTTC

TCCTATTATGATAACTCGACTATGGTCACCGGGAATGCTACCAGAGACCTGACACTTCATCAGACCGCCA

CACAGCACATGGTGACCAACGCGTCCGCTGTTCCTTCCGACTGTCCCAGTGAAGACAAAGACCTCCTGAA

TGAAAACGTGCAAGTTGGTCTGTTGTTTGCCTCGAAAGCCACCGTCCAGCTCATCACCAACCCTTTCATA

GGACTACTGACCAACAGAATTGGCTATCCAATTCCCATATTTGCGGGATTCTGCATCATGTTTGTCTCAA

CAATTATGTTTGCCTTCTCCAGCAGCTATGCCTTCCTGCTGATT- 


\section{GCCAGGTCGCTGCAGGGCATCGGCTC}

GTCCTGCTCCTCTGTGGCTGGGATGGGCATGCTTGCCAGTGTCTACACAGATGATGAAGAGAGAGGCAAC

GTCATGGGAATCGCCTTGGGAGGCCTGGCCATGGGGGTCTTAGTGGGCCCCCCCTTCGGGAGTGTGCTCT

ATGAGTTTGTGGGGAAGACGGCTCCGTTCCTGGTGCTGGCCGCCCTGGTACTCTTGGATGGAGCTATTCA

GCTCTTTGTGCTCCAGCCGTCCCGGGTGCAGCCAGAGAGTCAGAAGGGGACACCCCTAACCACGCTGCTG

AAGGACCCGTACATCCTCATTGCTGCAGGCTCCATCTGCTTTGCAAACATGGGCATCGCCATGCTGGAGC

CAGCCCTGCCCATCTGGATGATGGAGACCATGTGTTCCCGAAAGTGGCAGCTGGGCGTTGCCTTCTTGCC

AG C TAG TAT C TC T TATC T CAT T G GAACCAATAT T T T TGGGATACTTGCACACAAAATGGGGAGGTGGCTT

TGTGCTCTTCTGGGAATGATAATTGTTGGAGTCAGCATTTTATGTATTCCATTTGCAAAAAACATTTATG

GACTCATAGCTCCGAACTTTGGAGTTGGTTTTGCAATTGGAATGGTGGATTCGTCAATGATGCCTATCAT

GGGCTACCTCGTAGACCTGCGGCACGTGTCCGTCTATGGGAGTGTGTACGCCATTGCGGATGTGGCATTT

TGTATGGGGTATGCTATAGGTCCTTCTGCTGGTGGTGCTATTGCAAAGGCAATTGGATTTCCATGGCTCA

TGACAATTATTGGGATAATTGATATTCTTTTTGCCССTCTCTGCTTTTTTCTTCGAAGTCCACCTGCCAA

AGAAGAAAAAATGGCTATTCTCATGGATCACAACTGCCCTATTAAAACAAAAATGTACACTCAGAATAAT

ATCCAGTCATATCCGATAGGTGAAGATGAAGAATCTGAAAGTGACTGAGATGAGATCCTCAAAAATCATC

AAAGTGTTTAATTGTATAAAACAGTGTTTCCAGTGACACAACTCATCCAGAACTGTCTTAGTCATACCAT

C C A T C C C T G G T G A A G A G TAA A A C C A A A G G T TAT TATTTCCTTTCCATGG

\section{Findings}

We evaluate the VMAT2 gene expression in people who were religious were compared to non-religious people, we have analyzed pray. But the people who were non-religious or less religious, activity and expression of the gene that makes them less than the fate of God, have less faith And only in cases where their lives are in crisis and also pray to God, much less participate in religious rituals such as reciting prayers. Of those who VMAT2 gene was expressed in them, 243 people were more religious and believe in God because this gene was expressed more in the people than others. But the number of those who are less VMAT2 gene was expressed, 243 people had the highest expression of this gene In fact, the 243 to 757 people were more religious and more of those people who believe in God and attend religious services, yet even they do not participate in religious ceremonies and they were upset by this behavior.

\section{Discussion}

Using the nucleotide sequence and VMAT2 gene expression among the 2,000 participants of the study, It found that the more genes to be expressed, as well as the talented people being

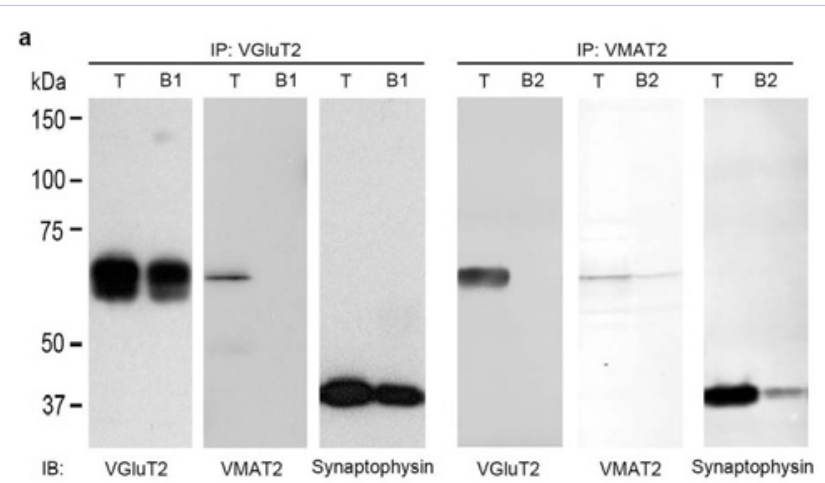

b

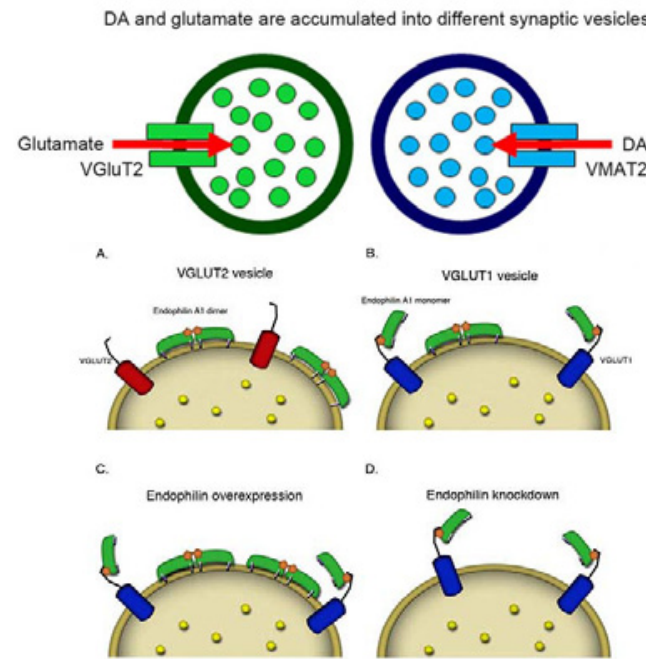

Figure 14: Schematic view of banding patterns and gang genes VMAT2 and VGLUT2.

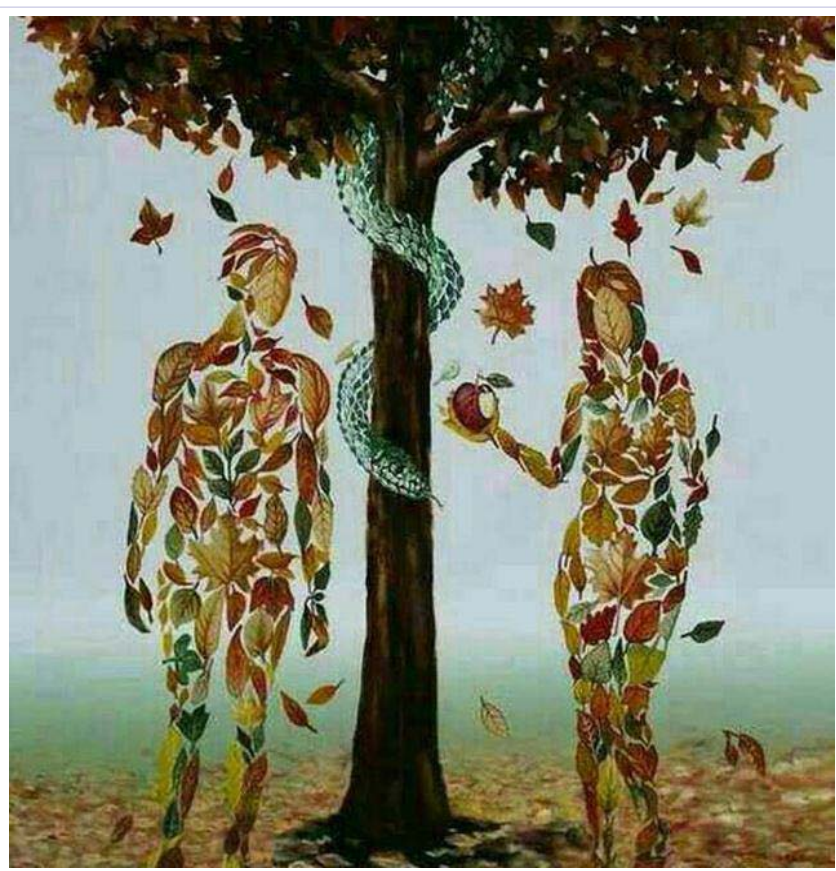

Figure 15: Schematic view of Adam and Eve expelled from paradise and while eating apples and descend to earth to God's command. 
religious and belief in God and the hereafter will be even more. But the important thing about this is that, living environment and ecosystem of life and lifestyle affect the expression of this gene. In other words, with the performance and activity of the gene VMAT2, being religious in human beings is remarkable, But the lifestyle and living ecosystem can also increase or decrease the speed performance of these genes play an important role. It is noteworthy that the DNA molecule also has memory and can be due to environmental conditions and lifestyle in certain time periods, the expression or activity, and this was very evident in this study. Because most religious people in the study were religious families and their parents also participated in religious ceremonies ever. However, even though this religious family they participated in religious ceremonies, But some of them have children who do not attend religious ceremonies were never in the same memory or memory is in the DNA molecule. Belief in God and worship him, a natural need and man's inner state that Adam and Eve Angel, has been retained to this day. Even decades of Communist Party rule in the world, could this natural need of the human and spiritual surrender. Most people do when they are experiencing social unrest, environmental damage, remember God is more obvious for him. And in such situations the natural need of the human and esoteric activity of several genes, is written. But a gene crucial role to play in this need of God and the name of the gene VMAT2 is. We worship God in this study was to evaluate the activity of the genes or gene known as VMAT2 God we analyzed Through the measurement of gene expression and activity of man's belief in God and religious leanings understand them. And the role of this gene in the human being religious, we have evaluated. In this study of 2,000 people of whom 1,000 religious and 1,000 others were less religious were analyzed.

\section{Acknowledgments}

Thanks to everyone who helped us in this study are very grateful. Certain professors of all universities of medical sciences and psychology thank country.

\section{References}

1. Hamer. Dean. The God Gene: How Faith Is Hardwired Into Our Genes. Anchor Books. 2005.

2. PZ Myers. No god, and no 'god gene', either" Pharyngula. 2005.

3. Zimmer Carl. "Faith-Boosting Genes: A search for the genetic basis of spirituality". 2004.

4. The 'God Gene' Sales Stunt. 2007.

5. Geneticist claims to have found 'God gene' in humans.

6. Hamer. Dean. The God Gene: How Faith Is Hardwired Into Our Genes. Anchor Books. 2005.

7. Womack Mari. Symbols and meaning : a concise introduction. Walnut Creek. et al. Altamira Press. p. 81. ISBN 0759103224. Retrieved 16 August 2013. Creation myths are symbolic stories describing how the universe and its inhabitants came to be. Creation myths develop through oral traditions and therefore typically have multiple versions. 2005.

8. Levenson Jon D. "Genesis: introduction and annotations". In Berlin, Adele, Brettler, Marc Zvi. The Jewish Study Bible. Oxford University Press. ISBN 9780195297515. 2004.

9. Graves Robert, Patai, Raphael. Hebrew Myths: The Book of Genesis. Random House. p. 315. 1986.

10. Schwartz Howard, Loebel Fried Caren, Ginsburg Elliot K. Tree of Souls: The Mythology of Judaism. Oxford University Press. p. 704. 2007. 